\title{
Conceptos de ciudadano, ciudadanía y civismo
}

\author{
Francisco Lizcano Fernández \\ Universidad Autónoma del Estado de México, Toluca, México. \\ Email: flizcanof@uaemex.mx
}

\begin{abstract}
Resumen: Este artículo distingue e interrelaciona dos concepciones de ciudadanía en relación con las colectividades soberanas o países: la jurídico-política y la ético-política. Para delimitar al ciudadano según la primera concepción, se divide a los habitantes en inmigrantes y nacionales, y a éstos en ciudadanos en sentido restringido y súbditos o nacionales sin derechos políticos (integrados por menores de edad y ciudadanos con los derechos políticos suspendidos). Respecto a la concepción ético-política, los habitantes son divididos en niños o inmaduros psicológicamente para la participación política y ciudadanos en sentido amplio, los cuales se dividen en pasivos y activos. Estos últimos se dividen a su vez en gremiales e ideológicos, los cuales pueden ser autoritarios y democráticos. Estas clasificaciones, con las definiciones correspondientes, se elaboran a partir de comparar lo dicho sobre los conceptos de ciudadano, ciudadanía y civismo en tres diccionarios de la lengua y en ocho obras lexicográficas especializadas.
\end{abstract}

Palabras clave: ciudadanía, ciudadano, civismo y democracia.

\section{Concepts of citizen, citizenship and civic}

Abstract: This article states the differences and relationships between two conceptions of citizenship_one concerned with juridical aspects and the other with ethical aspects_ in relation to sovereign communities or countries. To define the 'citizen' according to the first conception, inhabitants may be 1) immigrants or 2) nationals; nationals are subclassified as 2.1) citizens or 2.2) subjects, i.e., nationals without political rights (children and citizens with suspended political rights). According to the second conception, inhabitants are classified as 1) children or people psychologically unable to fulfill political participation and 2) citizens in broad sense; citizens are subclassified in 2.1) passive or 2.2) active. Active citizens may be either union citizens or ideological citizens, which can be authoritarian or democratic. These classifications and definitions are drawn from comparing what has been said about the concepts of citizen, citizenship and civic-mindedness in three language dictionaries and eight lexicographical dictionaries and encyclopedias.

Key words: citizenship, citizen, civic-mindedness, and democracy.

\section{Conceitos de cidadão, cidadania e civismo}

Resumo: Este artigo estabelece as diferenças e as relações entre duas concepções de cidadania - uma preocupada com aspectos jurídicos e outra com os aspectos éticos - em relação à soberania das comunidades ou países. Para definir cidadão de acordo com a primeira concepção, os habitantes podem ser 1) imigrantes ou 2) nacionais; nacionais são subgrupos de 2,1) os cidadãos ou 2,2) sujeitos, ou 
seja, cidadãos sem direitos políticos (crianças e cidadãos com direitos políticos suspensos). De acordo com a segunda concepção, os habitantes são classificados como: 1) crianças ou pessoas psicologicamente incapazes de cumprir a participação política e 2) os cidadãos em sentido amplo, os cidadãos são subclassificados em 2,1 ) passivos ou 2,2) ativos. Cidadãos ativos podem ser cidadãos, quer sindicais ou cidadãos ideológicos, o que pode ser autoritário ou democrático. Estas classificações e definições, são tiradas de comparar o que foi dito sobre os conceitos de cidadão, cidadania e civismo em três dicionários de língua e oito lexicográfica dicionários e enciclopédias.

Palavras-chave: cidadão, cidadania, civismo e democracia

$$
* * *
$$

El propósito de este texto consiste en ofrecer definiciones claras y coherentes de los tres conceptos indicados en su título - ciudadano, ciudadanía y civismo - , lo que implica, en lo fundamental, distinguir al ciudadano en sentido amplio del ciudadano en sentido restringido (lo que exige delimitar los estratos sociopolíticos integrados por ambos tipos de ciudadanos), así como establecer una serie de clasificaciones aplicables a los ciudadanos en los dos sentidos indicados. Esta tarea se enfrenta, más directa e integralmente, en el tercer apartado, "Distinciones y definiciones”, pero se basa en los análisis comparativos que de los tres conceptos señalados en el título del presente texto hacen tres diccionarios de la lengua, a los que se dedica el primer apartado, y ocho obras lexicográficas especializadas, a las que se dedica el segundo apartado.

Este ejercicio conceptual no sólo tiene el relieve teórico que le es inherente, sino que también pretende contribuir a la construcción de un marco teórico que ayude a fortalecer el trabajo en equipo de algunos grupos de investigación de la Universidad Autónoma del Estado de México que tienen configuraciones disciplinarias dispares. Con todo, más allá de los motivos concretos por los que se elaboraron, estas reflexiones pueden resultar útiles tanto para diversos estudiosos de las ciencias sociales y las humanidades como para los ciudadanos en general, pues pueden contribuir a una más precisa comprensión de conceptos que se emplean cada vez con mayor frecuencia, pero que no están exentos, como tantos otros, de dosis no desdeñables de ambigüedad. Las aportaciones del presente texto se concentran en el tercer apartado, pues contiene una clara dosis de originalidad tanto el conjunto de lo allí planteado como algunas de sus partes (por ejemplo, las distinciones entre ciudadano en sentido restringido y sentido amplio, así como entre ciudadano democrático y ciudadano autoritario). No obstante, también podría encontrarse cierta novedad en las comparaciones empleadas para ordenar la información de los dos apartados previos.

Dos comentarios para concluir esta introducción. Por un lado, las distinciones y definiciones contenidas en las distintas partes de este trabajo se refieren, principalmente, a las colectividades soberanas de las últimas décadas, que encuentran en el Estado social y democrático de derecho su expresión más laudable, al margen de que algunas de ellas puedan ser útiles 
para una mejor comprensión de las sociedades y los regímenes políticos previos. Por otro lado, el predominio de las citas textuales sobre las de resumen, que en general no es recomendable en los textos científicos, se debe sobre todo al tipo de fuente utilizado: obras lexicográficas, en ocasiones de difícil acceso en algunos países, que, por su misma naturaleza, pretenden ofrecer información de la manera más sintética posible. La pretensión de retomar toda la información relevante para los propósitos de este trabajo, el convencimiento de que la tarea emprendida sólo podía cumplirse cabalmente a través de comparaciones sistemáticas, así como la pretensión de evidenciar las deudas y las aportaciones que respecto a las obras analizadas tienen las ideas expuestas en el tercer apartado condujeron al mencionado uso frecuente de las citas textuales.

\section{Diccionarios de la lengua}

En las obras de consulta a las que se refiere este apartado, los términos ciudadano, ciudadanía y civismo comparten su referencia a colectividades generadoras de sentimientos de pertenencia entre sus integrantes, lo que sin duda está vinculado con su común procedencia etimológica: la palabra latina civitas, de donde, a su vez, procede el vocablo español ciudad. Sin embargo, estas palabras (y sus distintas acepciones) se refieren a dichas colectividades de formas distintas. En principio, cabe distinguir dos campos semánticos al respecto. Por un lado, el referido a la pertenencia a dicha colectividad — cuando no también a las características que implica dicha pertenencia - , pertenencia que, como veremos, de una forma u otra siempre lleva consigo el reconocimiento de cierto estatus o posición social. Por otro lado, la actitud o el comportamiento que deben tener los integrantes de tal colectividad por el hecho de pertenecer a ella; es decir, la actitud considerada como deseable, moral o ética para la colectividad en cuestión. De acuerdo con esta perspectiva, el vocablo ciudadano se circunscribe al primer campo semántico; ciudadanía puede aludir a los dos; y civismo se reduce al segundo.

Las acepciones de ciudadano y ciudadanía que se ubican en el primer campo semántico, el relativo a la pertenencia a determinadas colectividades, admiten dos clasificaciones. No obstante, antes de indicarlas, conviene recordar dos cuestiones interrelacionadas que se refieren al sentimiento de pertenencia. Por un lado, este sentimiento provoca, simultáneamente, unión y separación entre personas y colectividades: cohesiona a los integrantes de una misma colectividad, pero, al mismo tiempo, los separa, inexorablemente, de quienes no pertenecen a ella. Por otro lado, esta diferenciación de colectividades implica que los integrantes de cada una de ellas tienen estatus diferenciados, lo que a su vez refuerza la cohesión al interior de la colectividad y su separación de las otras colectividades.

La primera clasificación, de menor trascendencia que la siguiente, se basa en el grado de autonomía de las colectividades que son objeto de tal sentimiento de pertenencia, y permite diferenciar entre el sentimiento de 
pertenencia que involucra una colectividad soberana, el cual está asociado al estatus común de sus ciudadanos que los separa de los ciudadanos de otras colectividades del mismo tipo, y el que involucra colectividades políticamente dependientes, como las ciudades que forman parte de un país, a cuyos integrantes se les reconoce, implícita o explícitamente, un estatus diferente al de quienes tienen otro hábitat, como los campesinos, dentro de la misma colectividad soberana. Por tanto, en el primer caso el estatus otorgado por la ciudadanía diferencia individuos de distintas colectividades soberanas, mientras que en el segundo dicho estatus distingue individuos de distintos hábitats de la misma colectividad soberana. ${ }^{1}$

La segunda clasificación evidencia que algunas acepciones de los términos ciudadano y ciudadanía aluden a la totalidad de los integrantes de la colectividad de que se trate (incluidos, lógicamente, los niños), lo que podría calificarse como ciudadanía en sentido amplio (o habitantes), mientras que otras acepciones, que podrían calificarse de ciudadanía en sentido restringido, sólo se refieren a una parte de ella, al excluir a otra porción. Entre los excluidos, siempre se encuentran los niños, pero también pueden estarlo las mujeres, los estratos sociales de menor ingreso o los delincuentes. En el primer caso, al no establecerse diferencias al interior de la colectividad, todos sus integrantes comparten el mismo estatus, por lo que éste no puede implicar distinciones dentro de la colectividad en cuestión, sino entre quienes pertenecen y no pertenecen a ella. En el caso de las colectividades soberanas, definir al ciudadano como habitante de un país implica distinguir a todos sus habitantes de los ciudadanos de otros países. En el caso de colectividades políticamente dependientes, definir al ciudadano como el habitante de la ciudad implica conferir a todos los habitantes de la ciudad un estatus distinto al de los pueblerinos o habitantes del campo. En sentido restringido, la ciudadanía sólo abarca a una parte de la colectividad, lo que implica que los ciudadanos tienen un estatus distinto al del resto de los integrantes de su propia colectividad, independientemente de que también se distingan, como en el caso de los ciudadanos a los que alude el sentido amplio del concepto, de los habitantes de otras colectividades soberanas o políticamente dependientes. Las acepciones de ciudadano y ciudadanía que aluden a la ciudadanía en sentido amplio son más escuetas, pues identifican la ciudadanía con ser habitante de la colectividad de que se trate (ciudad, Estado o país), en tanto que el sentido restringido de ciudadanía proviene de la enunciación de las características que deben tener los habitantes de una colectividad para poder ser considerados como ciudadanos.

Como se indicó, todas las acepciones que nos interesan del vocablo ciudadano $^{2}$ se inscriben en el campo semántico relativo a la pertenencia, pero cabe clasificarlas por sus sentidos amplio o restringido. También cabe hacer esta misma clasificación de las acepciones de ciudadanía referidas a este mismo campo semántico. En el sentido amplio de ciudadanía se inscriben las dos siguientes acepciones de ciudadano de la RAE (2012b): "natural o vecino de una ciudad" y "perteneciente o relativo a la ciudad o a los ciudadanos”. Una de las dos acepciones de ciudadano de Lara (2010) es 
de este mismo tipo: “habitante de una ciudad”. Por su parte, Vox (2012) plantea al respecto las dos siguientes acepciones, que en el primer caso incluye ejemplos: “de la ciudad o sus habitantes, o relacionado con ellos: la seguridad ciudadana; la colaboración ciudadana” y "que ha nacido o que vive en una ciudad”.

Otras dos acepciones de ciudadano de la RAE (2012b) tienen sentido restringido. Una se refiere a tiempos pretéritos: "habitante libre de las ciudades antiguas”. La otra se emplea hoy con frecuencia: “persona considerada como miembro activo de un Estado, titular de derechos políticos y sometido a sus leyes". ${ }^{3}$ Lara (2010) define: “persona que, por tener la nacionalidad de un país, tiene los derechos y las obligaciones que sus leyes determinan: ciudadano mexicano, ciudadana cubana”. Por su parte, la tercera y última acepción de este vocablo en Vox (2012) señala: "habitante de un estado con una serie de derechos políticos y sociales que le permiten intervenir en la vida pública de un país determinado: ciudadano salvadoreño”.

En cuanto a las acepciones de ciudadanía integrantes del primer campo semántico al que nos estamos refiriendo, cabe distinguir entre las que tienen sentido restringido y las que son ambiguas al respecto por aludir a los ciudadanos sin especificar si se hace en sentido amplio o sentido restringido. Las dos contempladas por RAE (2012b) son ambiguas: "cualidad y derecho de ciudadano" y "conjunto de los ciudadanos de un pueblo o nación”. Vox (2012) proporciona una en sentido restringido y otra ambigua: “condición que reconoce a una persona una serie de derechos políticos y sociales que le permiten intervenir en la política de un país determinado: el derecho constitucional del voto ha constituido para muchas personas la condición de ciudadanía plena” y “conjunto formado por los ciudadanos de una nación o de un pueblo: la ciudadanía local; la ciudadanía de ultramar”. Por último, las dos únicas acepciones de ciudadanía proporcionadas por Lara (2012) pueden inscribirse en el sentido restringido, debido a los ejemplos seleccionados para ilustrar las definiciones: "conjunto de ciudadanos de un Estado: 'la ciudadanía lo eligió presidente', 'hay malestar en la ciudadanía por los actos autoritarios”” y "calidad y derecho de los ciudadanos: alcanzar la ciudadanía, recibir la ciudadanía”.

En los tres diccionarios revisados para este apartado, sólo se encuentran dos acepciones de ciudadanía asociadas al segundo campo semántico, vinculado con comportamiento deseable en un ciudadano hacia su colectividad: “comportamiento propio de un buen ciudadano” (RAE, 2012b) y "comportamiento de la persona que cumple con sus obligaciones de ciudadano dentro de su comunidad: un ejemplo de ciudadanía” (Vox, 2012).

En relación con el vocablo civismo, cuyas acepciones se inscriben íntegramente en el segundo campo temático, cabe hacer una distinción. Por un lado, las que aluden a actitudes: "celo por las instituciones e intereses de la patria” (RAE, 2012b) y “preocupación y cuidado por las instituciones e 
intereses de una nación” (Vox, 2012). Por otro lado, las referidas a comportamientos: "comportamiento respetuoso del ciudadano con las normas de convivencia pública” (RAE, 2012b), “comportamiento de la persona que cumple con sus deberes de ciudadano, respeta las leyes y contribuye así al funcionamiento correcto de la sociedad y al bienestar de los demás miembros de la comunidad: la cultura es algo más que erudición, es algo que se vincula con el civismo, con el comportamiento ordenado y responsable dentro de la comunidad" (Vox, 2012) y "comportamiento de los ciudadanos, correcto y acorde con las leyes, con el que manifiestan su interés por la vida nacional y su voluntad de participar en ella” (Lara, 2012).

Como se puede observar, para la elaboración de este capítulo, se seleccionaron tres fuentes. El Diccionario de la lengua española, elaborado por la Real Academia Española en colaboración con las 21 Academias que con la anterior conforman la Asociación de Academias de la Legua Española. Tal obra constituye el punto de referencia más importante respecto a la definición de las palabras del idioma español. La segunda obra (Vox, 2012) ha sido elaborada por Larousse, la empresa comercial de más prestigio y solera en el ámbito de los diccionarios de la lengua y las obras lexicográficas similares, se no se considera Espasa Calpe, cuya producción en este sentido está estrechamente vinculada al trabajo de la Real Academia Española. Por último, los dos volúmenes del Diccionario del español de México (Lara, 2010) conforman el principal esfuerzo realizado fuera de España para dar a conocer el vocabulario empleado en un país de lengua española, que, por cierto, es el que tiene el mayor número de hablantes de dicho idioma.

\section{Obras lexicográficas especializadas}

Para elaborar este apartado, se consultaron 19 obras lexicográficas. Quince pueden, sin duda, catalogarse como diccionarios especializados, en tanto que ordenan alfabéticamente las entradas de una determinada materia monográfica (Martínez de Sousa, 1995: 136-137). Las cuatro restantes podrían catalogarse de la misma manera a condición de que se sustituyera la expresión materia monográfica por la de ámbito específico de la realidad. Pero más atinadamente deben calificarse de enciclopedias alfabéticas (por tener este orden en lugar del temático, típico de las enciclopedias) especializadas (en lugar del carácter universal más propio de las enciclopedias) (Martínez, 1995: 136-137, 174-180). En lo que sigue la expresión obra lexicográfica especializada se emplea para aglutinar los diccionarios especializados y las enciclopedias alfabéticas especializadas. ${ }^{4}$

Dos comentarios al respecto. Primero: de los 15 diccionarios, 13 son disciplinarios, al referirse exclusivamente a antropología (2), filosofía (2), politología (4) y sociología (5), pero los dos restantes pueden ser calificados de temáticos, pues uno trata sobre ética y filosofía moral (CantoSperber, 2001) y el otro acerca de paz y conflictos (López, 2004). Segundo: la autoidentificación como enciclopedia de tres de las obras considera- 
das no se corresponde con lo que aquí se denomina enciclopedia alfabética especializada (ni con su tamaño), pues sólo una de las cuatro obras aquí catalogadas de esta forma se autoidentifica como enciclopedia (Sills; 1979). Las otras tres se autoidentifican como diccionarios. En cuanto al tamaño, de las cuatro aquí denominadas enciclopedias alfabéticas especializadas tres se componen de varios volúmenes (Campo, 1987, y Reyes, 2009, de cuatro; y Sills, 1979, de 11), pero la cuarta, sólo de uno (Tella, 1989). Por su parte, de las tres obras que se autoidentifican como enciclopedias dos se componen de dos volúmenes (Borja, 2002-2003; López, 2004) y sólo una es de mayores dimensiones (Sills, 1979).

De las 19 obras lexicográficas especializadas consultadas, únicamente 10 tienen entradas con alguno de los tres conceptos sobre los que versa el presente trabajo — ciudadanía, ciudadano y civismo —,${ }^{5}$ pero sólo 1 incluye el de civismo. Más concretamente, nueve contienen la entrada “ciudadanía”, si bien en una de ellas este vocablo se junta en la misma entrada con el de ciudadano (Nohlen, 2006: “ciudadanía/ciudadanos”). De las ocho obras restantes (se resta la de Nohlen a las nueve), cuatro sólo contienen la entrada “ciudadanía”, con esta misma y única formulación (Abercrombie, 1986; Abbagnano, 2008; Giner, 1998; Tella, 1989); dos añaden la entrada “ciudadano” como independiente (Borja, 2002-2003; Campo, 1987) y dos más añaden la de “ciudadano del mundo” (López, 2004) y la de "ciudadanía multicultural” (Baca y otros, 2000) a la de "ciudadanía”. Quedan dos entradas por mencionar: la enciclopedia dirigida por Reyes sólo incorpora el término “ciudadanía europea”, mientras que el dirigido por Nohlen (2006) es el único que incluye la de “civismo”. Incluida esta última, en total son 15 entradas en las 10 obras mencionadas en este párrafo, las cuales están integradas por tres diccionarios de politología (Nohlen, 2006; Borja, 2002-2003; Baca y otros, 2000), dos diccionarios de sociología (Abercrombie, 1986; Giner, 1998), un diccionario de filosofía (Abbagnano, 2008), un diccionario temático (López, 2004) y tres enciclopedias (Campo, 1987; Reyes, 2009; Tella, 1989). ${ }^{6}$

Sin embargo, debido a que cuatro entradas no contienen información relevante para los propósitos del presente trabajo (González Vega, 2009; Baca, 2000; Sánchez, 2004; y Martínez, 2004), no se las analiza ni compara con el detalle de las otras. Por tanto, después de la rápida mención que enseguida se hace de estas cuatro entradas, en lo que sigue sólo me referiré a ocho obras lexicográficas y 11 entradas, de las cuales 10 tratan sobre ciudadanía (o ciudadano) y sólo una sobre civismo. En la comparación en la enciclopedia dirigida por Reyes el contenido de la única entrada que incluye alguno de los conceptos sobre los que versa este texto se circunscribe por completo a un tema que ahora no interesa, la ciudadanía europea (González Vega, 2009). Por su parte, una de las dos entradas de Léxico de la política (Baca y otros, 2000), titulada “ciudadanía multicultural”, en lo fundamental se limita a confrontar dos concepciones de ciudadanía: la clásica y homogeneizadora, que el último tramo de su secular historia ha tenido raigambre liberal, y la multicultural. "El desafío político más importante, en consecuencia, consiste en conjugar las diferen- 
cias regionales con los criterios generales de la ciudadanía o, dicho de otra forma, en combinar las identidades particulares con una identidad colectiva más general, y es aquí donde aparece la necesidad de una nueva concepción de ciudadanía que incorpore las diferencias” (Baca, 2000: 56). Por último, las dos entradas de la obra dirigida por López (2004) defienden una ciudadanía universal que termine con el etnocentrismo, el racismo y el nacionalismo que han caracterizado las concepciones de ciudadanía predominantes a lo largo de la historia de la humanidad, pues hasta la fecha han demostrado su carácter excluyente. Sin embargo, este antiguo ideal se presenta aderezado de elementos poco afortunados como explicaciones simplistas: "la intolerancia de unos Estados contra otros hoy no es real sino un pararrayos para desviar la atención de los conflictos internos” (Sánchez, 2004: 124); y propuestas ingenuas cuya puesta en práctica podría traducirse en el incremento de los males que pretenden extirparse: "parece ser que para los ciudadanos del mundo más que leyes de extranjería se necesitan leyes de hospitalidad que regulen la posesión común de la tierra, ya que nadie tiene más derecho que otro a estar en un determinado lugar de la tierra” (Martínez, 2004: 126).

Antes de dejar que hablen las entradas de las obras lexicográficas especializadas que enfrentan la caracterización de alguno de los tres conceptos sobre que versa el presente trabajo, es necesario indicar dos criterios que se emplearon, respectivamente, para delimitar la información por rescatar y para clasificarla. Por un lado, sólo se retomó lo relativo a los significados actuales de los conceptos que aquí interesan. En consecuencia, se retoma lo dicho en estas obras sobre la construcción histórica de la ciudadanía tal como se concibe hoy, pero se excluye lo dicho sobre la ciudadanía en tiempos anteriores, como en la civilización grecolatina de la Antigüedad o en la Edad Media, de la que hablan con cierta amplitud seis entradas: Blasco, 1987; Hernández-Rubio, 1987; Bobes, 2000; Baca, 2000; Borja, 2002-2003: “Ciudadanía”; Martínez Guzmán, 2004. En cuanto al concepto actual de ciudadanía, relativo en lo fundamental a colectividades soberanas, conviene señalar desde ahora que incorpora, por lo menos, los tres tipos de derechos establecidos por Marshall (1997) en 1950 y que por tanto, en sentido estricto, sólo puede detectarse con el Estado social y democrático de derecho: ${ }^{7}$ en los Estados dictatoriales o bien no se preocupan por ninguno de los tres tipos de derechos o bien sólo lo hacen por los derechos sociales (como los leninistas), pues las dictaduras, independientemente de que sean de izquierda o de derecha, violan sistemáticamente los derechos individuales y los derechos políticos. Como dice una de las obras analizadas, "si entendemos por ciudadanía el conjunto de derechos cívicos, económicos y políticos, sólo las sociedades democráticas pueden considerarse legítimamente como sociedades de ciudadanos" (García Cabeza, 1998: 108).

De acuerdo con el enfoque predominante en ellas, las 11 entradas expuestas a continuación se dividen en dos grupos principales: siete, contenidas en cinco obras, se refieren a los términos ciudadanía o ciudadano bajo una óptica, básicamente, jurídico-política (las dos entradas de Borja, 
2002; Abercrombie y otros, 1986; Tella, 1989; García Cabeza, 1998; Hernández-Rubio, 1987; y Blasco, 1987); mientras que las cuatro entradas restantes (Bobes, 2000; Rieger, 2006; Nohlen, 2006; Abbagnano, 2008), contenidas en tres obras y que incluyen la única relativa a civismo, dan amplia cabida al enfoque ético-político o incluso se enmarcan plenamente en él. Además de las definiciones y distinciones que más interesan en este trabajo, se rescatan asuntos aledaños que también se consideran relevantes, como la construcción histórica del actual concepto de ciudadanía y las distintas percepciones desde las que se ha comprendido tal concepto. Como se observará, no se ha omitido valorar la precisión conceptual de los textos analizados, al señalar la ambigüedad de algunas formulaciones, que quizá proceda de la contenida, como se tuvo oportunidad de indicar, en algunas acepciones de ciudadanía de los diccionarios de la lengua, por más que en éstos la ambigüedad se debía a la falta de distinción entre habitante y ciudadano, en tanto que en estas obras especializadas suman a ésta la confusión entre estatus y comportamiento, entre derecho a participar y participación activa.

Borja (2002) ${ }^{8}$ hace dos distinciones respecto al término ciudadanía, a través de las cuales se plasman definiciones relativamente unívocas —desde el enfoque jurídico-político, lógicamente- de ciudadanía (con dos significados), ciudadano y nacionalidad. La única ambigüedad reseñable, que se mantiene en diferentes partes de la entrada, se debe a que en ocasiones no queda claro si para ser ciudadano se requiere sólo tener ciertos derechos y obligaciones o si, además de lo anterior, es necesario participar activamente en política. La primera distinción es usual tanto en este tipo de diccionarios como en los de la lengua. Sin embargo, como la definición de ciudadano de Borja es precisa esta distinción no da lugar a las ambigüedades que se encuentran en otros autores. Según este autor, la palabra ciudadanía "tiene dos acepciones: la primera se refiere al conjunto de ciudadanos de un Estado, y la segunda al cúmulo de derechos y deberes políticos que cada uno de ellos tienen” (Borja, 2002: 176). Mas adelante detalla esta segunda acepción de ciudadanía e incorpora la definición de ciudadano: "el cúmulo de derechos y obligaciones políticos que ellos [los ciudadanos] tienen como elementos políticamente activos de la vida estatal. Dicho en otras palabras, es el conjunto de deberes y derechos recíprocos entre los agentes y órganos estatales y las personas definidas en su función de su pertenencia al Estado. No toda persona es ciudadano: lo es solamente la que reúne determinadas condiciones de nacionalidad, edad y ejercicio de los derechos políticos” (Borja, 2002: 177). La segunda distinción es entre nacionalidad y ciudadanía.

No se deben confundir los conceptos nacionalidad y ciudadanía. La nacionalidad es una especial condición de sometimiento político de una persona a un Estado determinado, sea por haber nacido en su territorio, sea por descender de padres naturales de ese Estado, sea por haber convenido voluntariamente en sujetarse políticamente a él. La ciudadanía, en cambio, es la calidad que adquiere el que, teniendo una nacionalidad y habiendo cumplido las condiciones lega- 
les requeridas, asume el ejercicio de los derechos políticos que le habilitan para tomar parte activa en la vida pública del Estado y se somete a los deberes que le impone su calidad.

Por tanto, está claro que no puede haber ciudadanía sin nacionalidad, puesto que ésta es condición necesaria para aquélla, pero sí puede haber nacionalidad sin ciudadanía, como en el caso de los menores de edad o de los adultos interdictos por cualquier causa, que pertenecen al Estado pero que no tienen el uso de los derechos políticos (Borja, 2002: 177).

También es clara, por más que pudiera discutirse, la distribución de derechos que hace entre los distintos estratos sociopolíticos de un país.

A la persona le asisten dos clases de derechos: unos que le son inherentes por su calidad humana, y que por tanto son comunes a todas las demás personas, y otros que le pertenecen en cuanto elemento políticamente activo del Estado, es decir, en cuanto ciudadano.

Dentro de esta doble consideración del individuo - como persona humana y como ciudadano-, los primeros son los derechos civiles, los derechos sociales y los nuevos derechos del ser humano, que se extienden a todos los individuos, nacionales o extranjeros, mayores o menores de edad, que habitan en el territorio del Estado, y los segundos son los derechos políticos, que pertenecen exclusivamente a la persona en cuanto miembro activo de la vida política del Estado (Borja, 2002: 176-177).

Más adelante insiste y concreta (al autor podría achacársele, sin demeritar sus virtudes, cierta dificultad de síntesis)

Los derechos civiles se conceden en forma amplia y general a todas las personas sin distinción de raza, edad, sexo, idioma, religión, opinión política, origen nacional, posición social, capacidad económica o cualquier otra condición. Los derechos políticos, en cambio, se asignan solamente a los nacionales y, dentro de ellos, únicamente a los que tienen la calidad de ciudadanos. No todos los habitantes de un Estado son ciudadanos. Lo son tan sólo aquellos que han cumplido los requisitos generales que la ley exige para la obtención de la ciudadanía, que es una calidad jurídico-política especial que acredita a la persona como miembro activo del Estado y que la habilita para ejercer los derechos políticos, es decir, para participar en la vida pública estatal (Borja, 2002: 177).

Desde este entendimiento de la ciudadanía, como “un status jurídico que entraña una serie de derechos políticos de las personas en la vida comunitaria” (Borja, 2002: 177), el autor, con un detalle que merece ser rescatado, establece los requisitos que deben reunir los individuos para convertirse en ciudadanos, tras lo cual menciona algunas causales de sus- 
pensión de la ciudadanía y algunos derechos políticos concretos.

Las legislaciones establecen los requisitos que deben reunir las personas para adquirir y ejercer los derechos políticos o de ciudadanía. El primero de ellos es la nacionalidad, que entraña un vínculo jurídico-político entre un individuo y un Estado determinado, ya por haber nacido en su territorio o ya por haberse naturalizado en aquél. No tienen derechos políticos más que los nacionales de un Estado. Los extranjeros no. La nacionalidad puede ser de dos clases: de origen y adquirida. Nacionalidad de origen es la que pertenece al individuo por el solo hecho del nacimiento en el territorio de un Estado. Nacionalidad adquirida es la que obtiene la persona por un acto voluntario mediante el cual cambia su nacionalidad de origen por otra. Esto significa que se puede pertenecer a un Estado por nacimiento o por naturalización. En cualquier caso, la nacionalidad impone al individuo determinados deberes para con el Estado al mismo tiempo que le confiere ciertos derechos, que son los derechos políticos, entre los cuales está el electoral.

El segundo requisito es el de la edad. Para ser ciudadano, es decir, elemento políticamente activo del Estado, se requiere haber cumplido la edad mínima señalada por la ley, que varía según las legislaciones entre 16 y 21 años. Esta exigencia representa una presunción de madurez en la persona para efectos de asignarle funciones y responsabilidades públicas.

Los derechos de ciudadanía se suspenden por condena judicial en razón de la comisión de un delito, por enajenación mental y, en algunos Estados, por el alistamiento en las fuerzas armadas o por el ingreso al clero.

Son derechos políticos: el de participar en el gobierno del Estado, de elegir y ser elegido, tomar parte en plebiscitos, referendos, recalls y otras formas de consulta popular; desempeñar funciones públicas, militar en partidos políticos, opinar y expresar libremente las opiniones sobre cuestiones del Estado y los demás referentes a la vida política y de la comunidad (Borja, 2002: 177-178).

En la misma perspectiva jurídico-política de Borja, se inscriben las tres entradas mencionadas a continuación (Abercrombie y otros, 1986; Tella, 1989; García Cabeza, 1998). La primera se encuentra en un diccionario de sociología publicado originalmente en inglés en la primera mitad de la década de 1980, y, entre otras cuestiones, presenta con claridad, además de las características básicas de la ciudadanía actual —los derechos civiles, políticos y socioeconómicos-, una visión histórica de cómo se obtuvieron tales derechos y de las repercusiones sociopolíticas que tuvieron.

El concepto de ciudadanía como condición que da acceso a derechos y poderes está asociado con T. H. Marshall (1963). Los dere- 
chos civiles comprenden la libertad de expresión y la igualdad ante la ley. Los derechos políticos incluyen el derecho al voto y a organizarse políticamente. Los derechos socio-económicos incluyen el bienestar económico y la seguridad social. En la sociedad preindustrial, esos derechos estaban limitados a una élite reducida. Mientras la masa se vio excluida del disfrute de plenos derechos civiles y políticos, florecieron las ideologías revolucionarias de clase. La extensión de la ciudadanía en el sentido civil y político a la burguesía y a la clase trabajadora integró a estas clases en la sociedad y la política, lo que llevó al declive de la conciencia revolucionaria de clase. La extensión de los derechos socioeconómicos, incluidos el de sindicarse, el de negociar colectivamente en la esfera económica y el crecimiento del Estado del bienestar, puede considerarse también importante para la integración de la clase trabajadora moderna (Abercrombie y otros, 1986. 44).

La segunda entrada, tan clara como la anterior pero más escueta que ella, pertenece a una obra colectiva realizada, en la segunda mitad de la década de 1980, en Argentina, de donde son la mayoría de sus autores.

Ciudadanía. Calidad de ciudadano, o conjunto de personas de una población o país que reúnen los requisitos para ser considerados como tales, y por lo tanto tienen derechos políticos, fundamentalmente el de elegir y ser elegidos para las funciones gubernamentales, así como las obligaciones correspondientes. Las leyes de cada Estado establecen las condiciones en que se reconoce la ciudadanía a los nacionales que llegan a la mayoría de edad, y a los extranjeros que la solicitan (naturalización) (Tella, 1989: 77).

La tercera entrada, más extensa que las dos anteriores, se publicó al final del siglo XX en el primer diccionario de sociología elaborado íntegramente por autores españoles. De ella rescato la definición de ciudadanía y lo relativo a su construcción, aunque en los dos asuntos se exhiben ciertas ambigüedades: en el primero no se distingue suficientemente entre prácticas, documentos y derechos (y obligaciones), mientras que en el segundo no se hacen las debidas distinciones entre nacionalidad y ciudadanía.

La ciudadanía es aquel conjunto de prácticas que definen a una persona como miembro de pleno derecho dentro de una sociedad. La ciudadanía formal implica la posesión de un pasaporte conferido por el estado, mientras que la substantiva define el conjunto de derechos y obligaciones que tienen los miembros de una comunidad política. La ciudadanía implica obligaciones a cargo de las instituciones públicas par responder a los compromisos de participación de los derechos conferidos [...]. Desde finales del siglo XVIII fue consolidándose la ciudadanía como sinónimo de nacionalidad. Los estados fueron extendiendo la ciudadanía al tiempo que homogeneizaban la lengua y la educación para incorporar a sus poblaciones. La revolución industrial contribuyó al aumento de la con- 
ciencia política mediante la proliferación de asociaciones cívicas y de los sindicatos obreros. La participación en los procesos políticos fue exigida por los grupos sociales sin poder —los trabajadores y más tarde las mujeres-, adquiriendo derechos políticos que contribuirían a mejorar sus condiciones de vida. La extensión de la ciudadanía, como modo de inclusión, a la mayoría de los habitantes ha sido posible con la incorporación de los derechos sociales a este principio, gracias al desarrollo reciente de los estados de bienestar (García Cabeza, 1998: 107).

Por último, en este mismo enfoque jurídico-político se inscriben las dos entradas de la enciclopedia dirigida por Campos (1987), si bien en la de "ciudadano" se sugieren algunos elementos propios del enfoque integral. Ambas presentan ciertas ambigüedades, al confundir derecho a participar con participación activa, cuando no también nacionalidad y ciudadanía. En la entrada "ciudadanía”, después de no conseguir distinguir con claridad estos dos últimos conceptos, se afirma que la ciudadanía "significa el derecho a participar activamente en la vida política del Estado al cual se pertenece", para después sostener que "la participación como ciudadano en las funciones políticas del Estado integran la ciudadanía” (HernándezRubio, 1987:398). Con todo, se enfatiza un aspecto medular de la ciudadanía: "la ciudadanía encierra, pues, una relación de la persona con el Estado. La misma no se agota por la mera nacionalidad, que puede darse sin aquélla. El hombre ciudadano es, a diferencia del simple súbdito, un ser que participa de algún modo en la sociedad política” (Ibid: 399).

Asimismo, merece la pena reproducir en extenso lo que se señala a continuación sobre los derechos y deberes de la ciudadanía, sus orígenes jurídicos, así como su adquisición, pérdida y recuperación, pues completa lo dicho al respecto por Borja.

Derecho a la protección del Estado dentro y fuera del país; derecho de sufragio activo y pasivo; es decir, la capacidad de votar y ser elegido en las elecciones para cargos públicos políticos; el derecho de demandar y de ser oído en los tribunales de justicia. Deberes de cumplimiento de las leyes vigentes; de pago de las contribuciones legales; de prestación del servicio militar.

El concepto actual de la ciudadanía tiene sus raíces indudables en la ideología liberal-democrática y en el concepto de "Estado de Derecho" del siglo XIX. Los derechos del hombre "y del ciudadano" de la "Declaración" revolucionaria francesa de 1789 son su momento germinal, y la libertad política de participar en las funciones públicas y en el ejercicio del poder del Estado, bajo un orden legal establecido basado en una Constitución, constituyen su fundamento.

La ciudadanía puede adquirirse y perderse hoy de muy diversas maneras, según cada legislación y cada país. 
La forma normal de adquisición de la ciudadanía es el nacimiento, bien atendiendo al iussoli (nacimiento dentro del país) o al iussanguinis (derecho de sangre o de ascendencia) combinándose en la mayoría de las veces en las legislaciones ambos modos de adquirir la ciudadanía, según determinados requisitos concretos. También se adquiere por voluntad expresa o por voluntad presunta (como en este caso último, del matrimonio de una extranjera con un ciudadano nacional). Por residencia y obtención de la llamada carta de naturaleza o naturalización.

Formas de pérdida de la ciudadanía son la voluntad expresa de adquirir otra, distinta de la concedida por el país propio según su legislación; por voluntad presunta, como en el caso señalado del matrimonio. Por naturalización en un país extranjero, cuando así lo indique la legislación del país de origen. A consecuencia de una ley penal que así lo establezca, etc.

La ciudadanía puede recuperarse también, por ejemplo, por residencia en el país originario con voluntad expresa de readquirirla, o por la mujer casada con extranjero una vez disuelto el matrimonio. En estos casos se suele exigir una declaración pública oficial, y la renuncia a la nacionalidad extranjera. Por concesión especial de los Estados, etc.

Como puede inmediatamente apreciarse, la adquisición y la pérdida de la ciudadanía está inserta en la adquisición y pérdida de la nacionalidad, pues en realidad es ésta la que se adquiere o pierde, y a consecuencia de ello se adquiere o se pierde, o se recupera en su caso, la ciudadanía. La nacionalidad, es, pues, un concepto y una realidad más amplia (Hernández-Rubio, 1987: 398-399).

De la entrada de "ciudadano" de la obra dirigida por Campos pasamos por alto las partes donde incurre en las confusiones señaladas, para concentrarnos en su último párrafo, donde, entre otras cuestiones, se sugiere el enlace entre la perspectiva jurídico-política y la ético-política.

Así, pues, la condición de ciudadano confiere al individuo un "status" particular en el sistema socio-político. Naturalmente, dicho "status" va vinculado al correspondiente conjunto de "roles". A su vez, "cada uno de estos constituye un complejo de expectativas de comportamiento" y deberes (R. Dahrendorf: Homo sociologicus. Westdeutscher Verlag. Colonia y Opladen, 1964, pág. 26). En consecuencia, los derechos del ciudadano van unidos a sus correspondientes deberes (Blasco, 1987: 400).

En relación con la perspectiva ético-política de ciudadanía, que no está totalmente divorciada de la anterior porque incorpora elementos jurídico-políticos, integro cuatro entradas de tres obras: Bobes, 2000; Rieger, 
2006; Nohlen, 2006; y Galeazzi, 2008. Además de referirse a la construcción de la ciudadanía actual con una información que ya nos es familiar, Bobes ofrece, sin duda, ${ }^{9}$ la definición más completa de ciudadanía integral de las entradas consultadas, en una obra mexicana ambiciosa y bien elaborada, Léxico de la política.

La ciudadanía puede ser definida como un conjunto de derechos y deberes que hacen del individuo miembro de una comunidad política, a la vez que lo ubican en un lugar determinado dentro de la organización política, y que, finalmente, inducen un conjunto de cualidades morales (valores) que orientan su actuación en el mundo público.

Así planteada, la condición de ciudadanía nos enfrenta al menos con tres dimensiones que operan simultáneamente: $a$ ) una procedimental, que se refiere al conjunto de derechos y mecanismos para su ejercicio, constituido por un modelo de reglas, aplicadas y reconocidas igualmente para todos (y por todos), al que se encuentra ligado todo individuo por el solo hecho de ser un miembro de la comunidad; $b$ ) una dimensión de carácter situacional (o locativa) que implica a la vez un aspecto relacional. Esta dimensión apunta a un grupo de funciones a través de las cuales los individuos se ubican en la división del trabajo político. Aquí las interacciones entre individuos se establecen a partir del mutuo reconocimiento, y en razón de ello los hombres pueden esperar ser tratados (por el Estado y sus instituciones, y por los otros individuos) en condiciones de igualdad a partir de ciertos principios abstractos compartidos que definen la autoridad y las jerarquías; c) finalmente, existe una dimensión moral, que tiene que ver con un conjunto de ideas acerca de la vida pública y con los valores cívicos que orientan los comportamientos considerados adecuados o justos para la coexistencia y la acción pública (universalismo, igualdad, libertad individual, tolerancia, solidaridad, justicia, etcétera) (Bobes, 2000: 50).

También interesa rescatar cómo se plantea esta autora una serie de distinciones relacionadas entre sí y con las utilizadas en este apartado. En primer lugar, diferencia tres tradiciones: la liberal, la republicana y la democrática, si bien estas dos últimas no terminan de distinguirse con claridad. Posteriormente, se establecen otras distinciones que permiten vincular la ciudadanía militante, la ciudadanía como participación y, quizá, la ciudadanía activa con la tradición republicana, así como la ciudadanía civil, la ciudadanía como estatus y la ciudadanía pasiva con la tradición liberal.

En la tradición republicana se prioriza la vida pública, la virtud ciudadana y el bien público por encima de los intereses individuales; el liberalismo hace énfasis en el individuo, su libertad, su carácter privado y la necesidad de una ciudadanía que imponga controles a la acción estatal; por último, la tradición democrática se fundamenta en la participación, la justicia y el autogobierno [...]. 
Desde esta misma perspectiva también puede hablarse de una ciudadanía militante (activista) y de una civil. Más cercana a la tradición radical, la ciudadanía militante implica ante todo la membresía a un Estado, el compromiso público y la obligación dominante hacia éste; ésta sería una ciudadanía participativa, que entiende los deberes como el medio normal de ejercer los derechos. A su vez, la ciudadanía civil estaría basada en la moderación del compromiso público, y las obligaciones estarían dirigidas ante todo a la asociación, lo que implica una ciudadanía "más privada”, donde el sentimiento de pertenencia es más hacia lo particular, y el compromiso con el Estado se condiciona a que éste permita el ejercicio de la actividad privada. Mientras en la primera el individuo es considerado un agente político activo y se le estimula a intervenir en los asuntos públicos y en los procesos de toma de decisiones, en la segunda el ciudadano es considerado súbdito de una autoridad y su libertad se considera asociada sobre todo al ámbito privado.

Desde este mismo punto de vista puede discutirse la existencia de la ciudadanía como status - correspondiente a la tradición liberal individualista - frente a la ciudadanía que se define por su ejercicio y práctica - típica de la tradición cívico-republicana-. La primera pone énfasis en los derechos inherentes al individuo en cuanto tal y la dignidad humana; concede la primacía al individuo que elige o no ejercer esos derechos que le da el status, de donde resulta que la actividad política es una opción individual. La segunda es una concepción basada en la participación (ejercicio) y, por lo tanto, destaca los deberes. La definición del ciudadano se condiciona a la pertenencia a una comunidad política; los lazos interindividuales se basan en una forma de vida compartida y su libertad implica la coincidencia del deber y el interés individual. Aquí, la ciudadanía, más que un status, es una práctica, es activa y pública y, para esta tradición, la contradicción entre el interés público y el privado es inconcebible.

Entrando en una dimensión que aluda a los procesos históricos de su constitución, también es posible hacer una distinción entre las ciudadanías activas y las pasivas. Las primeras se forman "desde abajo” a partir de las instituciones participativas localizadas en la sociedad y como resultado de las luchas sociales y de las demandas (de la sociedad al Estado) de ampliación de derechos y mayor inclusión. Las ciudadanías pasivas, por su parte, se constituyen desde arriba vía el Estado, por efecto de la acción estatal, frecuentemente como resultado de la llegada al poder de élites interesadas en otorgar más derechos o en convertir a una mayor cantidad de individuos en sujetos de los ya existentes (Bobes, 2000: 51-52).

El Diccionario de Ciencia Política publicado por Porrúa (Nohlen, 2006a), al inicio de la entrada “ciudadanía/ciudadanos”, se plantea una definición confusa con dos posibles interpretaciones: o bien se refiere toda 
ella a los habitantes, con lo que no se estaría haciendo la debida distinción entre éstos y los ciudadanos, o bien el primer elemento alude a los habitantes y el segundo, a los ciudadanos: "la totalidad de los miembros de un ente político y su estatus como miembros de pleno derecho". Sin embargo, a continuación se hacen dos distinciones importantes. Por un lado, se afirma que "la forma y el contenido del concepto de ciudadana/o corresponde a la función e importancia de la unidad política de que se trate”, y diferencia al respecto tres niveles: el Estado nacional, el subestatal, el supra nacional. Respecto al primero - el de mayor relevancia actualmente y al que me ciño en el tercer apartado - se indican dos cuestiones: que "su adquisición está ligada a criterios estrictos (ascendencia, nacionalización)” y que en él la ciudadanía "garantiza un estatus seguro, con los mismos derechos fundamentales civiles, políticos y sociales (igualdad ante la ley, libertad de conciencia, libertad de asociación, sufragio, derecho a recibir asistencia social, etc.)” (Rieger, 2006: 2003).

Por otro lado, se distingue entre dos conceptos de ciudadanía, el liberal y el republicano, cuya oposición, de larga data, se habría revitalizado en la década de 1990.

El liberalismo considera al ciudadano definido esencialmente por los derechos de su libertad individual, como derechos de defensa del burgués frente al Estado. Los derechos políticos cumplen aquí el objetivo instrumental de delimitar y controlar el poder y los derechos sociales se justifican con la necesidad de asegurar y restablecer la autonomía individual. En cambio, el republicanismo concibe al ciudadano, en la tradición de la polis griega, como forma de vida en la cual el ciudadano se realiza a través de su compromiso a favor del bien común y la participación en la dominación (Rieger, 2006: 2003-204).

En contraposición también con la perspectiva liberal, el mismo autor afirma que

el comunitarismo acentúa en su crítica del concepto liberal de ciudadano que la democracia liberal y el Estado de bienestar descansan en presupuestos (valores comunes, cultura política, etc.) que ellos mismos no pueden mantener o establecer en la lógica de la libertad individual y la preeminencia del derecho ante lo bueno. La ciudadanía exige, afirman, un retorno al compromiso de los ciudadanos y sus virtudes, que tienen que fomentarse a través de la cultura política y la democracia directa (Rieger, 2006: 204).

A partir de la constatación de que, “con la sobrevaloración de la comunidad, existe el peligro a la inversa de una pérdida de la libertad individual”, se sostiene que

Para un concepto del ciudadano adecuado al mundo moderno se requiere un nuevo ajuste de la tensión insuperable entre (a) libertad, 
igualdad y solidaridad, (b) entre la orientación hacia el bien común y los derechos individuales, (c) entre los derechos humanos y los derechos civiles, y (d) entre los ciudadanos como comunidad política y pertenencias étnicas, religiosas, etc. (Rieger, 2006: 204).

En este mismo diccionario especializado en ciencia política, se incluye la única entrada dedicada al civismo de todas las obras lexicográficas especializadas consultadas. Si bien su contenido se circunscribe al tipo de interrelación que debe primar entre los políticos, sus afirmaciones enfatizan valores y comportamientos que también son aplicables a la interacción en la vida cotidiana de los habitantes de cualquier país.

Civilidad/Civismo, conceptos que designan un estilo de conducta política consistente en las buenas maneras, la cortesía y el respeto tanto frente a los aliados como frente a los opositores políticos.

A veces, la lucha política conduce a sus protagonistas, especialmente a los que ocupan cargos de gobierno, a denigrar a sus rivales, lesionando así su dignidad por el simple hecho de disentir o de oponerse políticamente. Esto no es sólo lamentable a nivel personal. Indica también un estado de cultura política poco acorde con la esencia del proceso político democrático como búsqueda de la mejor decisión en un marco de conflicto de intereses. Se desprecia la función de control que ejerce la oposición, uno de los pilares de la democracia representativa. Los conceptos c. y c. se asocian además a los de comprensión, moderación y gentileza, cualidades basadas en la estima y el respeto a otras personas. Su elemento sustancial consiste en la inclusión de los otros en mismo universo moral, en el tratamiento de otras personas como iguales, nunca como inferiores en dignidad, y en el reconocimiento de la función que cumplen los que se oponen y que, por lo demás, constituyen la alternativa de gobierno en el futuro (Nohlen, 2006b: 203-204).

Por su parte, la entrada dedicada a la ciudadanía en la última edición del diccionario de filosofía de Abbagnano, pese a sus ambigüedades, manifiestas por ejemplo en la definición del mencionado concepto, reitera distinciones importantes vistas ya en entradas anteriores, pero añadiendo matices rescatables, y expone con claridad los ingredientes involucrados en las nuevas formulaciones del concepto en cuestión.

La Ciudadanía es la pertenencia a una comunidad política, y se constituye en diversos términos en las diferentes sociedades. Está ligada a la libertad (concebida como parte del derecho natural, es decir, universal) o a la justicia (considerada como orden o igualdad), o a una y otra, y en este sentido se identifica con el ejercicio de tres clases de derechos humanos: los civiles (por ejemplo: a la vida, a la expresión y a la propiedad); los políticos (v.gr., al ejercicio electoral, a la asociación en partidos y sindicatos), y los sociales (entre otros, al trabajo, al estudio, a la salud). La adquisición de esos dere- 
chos de c., según algunos, es progresiva; según otros, no tiene carácter lineal ni evolutivo. Mientras que en la Antigüedad la idea de c. se relacionaba esencialmente con la de los deberes, y en la edad moderna, con la de los derechos, la idea de la c. abarca hoy derechos y deberes: considerados los unos y los otros coesenciales para ser miembros de una comunidad. Con mayor precisión podría decirse que la nueva c. reúne los derechos de la libertad y de la igualdad con los deberes de la solidaridad. En este sentido, el concepto de c. se une al de democracia, y se caracteriza por la necesidad de conciliar las exigencias de la participación con las de la gobernabilidad, por un lado, y por el otro, las de la justicia con las del mercado. A este respecto se habla de nueva c. con referencia a la necesidad de superar una cultura estatista (que conduce al Estado asistencial) en favor de una cultura social que va más allá del binomio Estadomercado, y se abre al trinomio Estado-mercado-tercer sector (el denominado sector no profit, de carácter social privado). Consiguientemente, la c. no se define en términos de reivindicación (por parte de los grupos) ni de donaciones (por parte del Estado), sino en términos de responsabilidad, en el sentido de corresponsabilización. En esta perspectiva, el problema de la c., objeto de estudio por parte de la sociología, se convierte en tema de reflexión, incluso para la filosofía política. A este respecto, interesantes indicaciones provienen de diversos autores, como R. Dahrendorf, quien en la c. ve la síntesis de libertad e igualdad, y J. Habermas, quien propone un concepto de C. que implica el ejercicio efectivo de los derechos civiles como oportunidad para que los ciudadanos tomen parte activa en los procesos deliberativos sobre derechos políticos y sociales. El problema de la c. va adquiriendo creciente importancia en las ciencias sociales o en la filosofía política, en cuanto representa la manera para dar carácter concreto al discurso sobre la democracia, evitando una configuración abstracta o genérica (Galeazzi, 2008: 168).

Para terminar este apartado, no deja de resultar interesante mencionar las 10 obras lexicográficas consultadas en ciencias sociales (sociología, politología y antropología) y filosofía que no incluyen (mejor decir incluían, en pasado, pues se contempla entre ellas el diccionario de Abbagnano, que desde su última edición incorporó, como se indicó, la entrada de "ciudadanía”) ninguna de las tres entradas de las que trata el presente texto — ciudadanía, ciudadano y civismo-, pues estas ausencias demuestran que el interés despertado por tales conceptos ha crecido con el tiempo, pero que todavía no ha llegado a disciplinas y ámbitos de reflexión que sacarían provecho de ello. Sin duda, la ausencia temprana más significativa es la de esa magnifica enciclopedia en 11 tomos que se culminó en su lengua original, la inglesa, en 1968, que todavía sigue consultándose con provecho por su elevada calidad y que es la más extensa de las 19 obras consultadas (Sills, 1979).

Los dos mejores diccionarios de filosofía en la actualidad son obra, 
en lo fundamental, de un sólo autor y vieron la luz hace unas cuantas décadas, aunque han tenido varias rediciones. El de Ferrater Mora (1990), escrito originalmente en español, vio la luz en México por primera vez, en 1941, con 598 páginas en un solo tomo. La última edición preparada por completo por su autor, la sexta, fue editada en 1979 por Alianza y consta de 3589 páginas divididas en cuatro tomos (Wikipedia, 2012). El de Abbagnano, que me parece más preciso en la expresión de las ideas que el anterior, tuvo su primera edición en su lengua original, el italiano, en 1961. La segunda edición y última preparada por el autor fue de 1971. El Fondo de Cultura Económica, además de publicar tales ediciones, lo ha hecho también con la tercera, actualizada y aumentada por Giovanni Fornero, donde aparece por primera vez el término ciudadanía, que se reseñó antes. Más sorprendente resulta que una obra dedicada a la ética y la filosofía moral, que vio la luz por primera vez en francés, a mediados del decenio de 1990, tampoco tenga estas palabras (Canto-Sperber, 2001).

En el campo de la sociología tres diccionarios traducidos al español desde otras tantas lenguas distintas se siguen vendiendo hoy, pese a sus distintas edades. Ninguno contiene las palabras que nos interesan en este trabajo: el más antiguo fue editado en inglés por primera vez en 1944 (Fairchild, 2006), el segundo tuvo su origen en Viena en 1969 (Schoeck, 1985) y el tercero se editó por primera vez en italiano en 1978 (Gallino, 2001).

Tampoco tienen estas entradas los que quizá sean los dos mejores diccionarios de antropología en español, publicados ambos en este siglo en esta lengua y en el decenio de 1990 en sus lenguas originales: uno en 1991 en francés (Bonte e Izard, 2005) y otro, verdaderamente ejemplar, en 1997 en inglés (Barfield, 2000). Otra obra que no puede dejar de mencionarse en este sentido es el que quizá sea el diccionario de ciencia política más leído en español, aunque es traducido del italiano, cuyas ediciones en su lengua original son de 1976 y 1983 (Bobbio y otros, 2002).

\section{Distinciones y definiciones}

El objetivo principal de este apartado consiste en establecer algunas relaciones básicas entre un concepto de ciudadanía derivado del enfoque jurídico-político y otro procedente del enfoque ético-político. Sin embargo, dichas relaciones sólo se hacen nítidas cuando se emprenden por separado las distinciones, definiciones y consecuencias propias de cada enfoque.

Antes de emprender estas tareas, conviene precisar algunos términos que se utilizan en el análisis de ambos conceptos de ciudadanía. En este texto ambos enfoques se aplican a un mismo tipo de colectividad que denomino país, entendido como colectividad soberana paradigmática en la actualidad y que habita un territorio claramente delimitado. ${ }^{10}$ Por su parte, con el vocablo habitante se alude a toda persona que vive de forma perma- 
nente en un país, por lo que este concepto aglutina todos los estratos sociopolíticos que se distinguen a continuación, desde cualquiera de las perspectivas empleadas. Dicho de otra manera, el conjunto de los habitantes se divide en estratos sociopolíticos. Pese a su amplitud, este concepto de habitante excluye a personas que podrían encontrarse en un país en un momento determinado, como las que están en transito hacia otro país o las que se encuentran en él por un lapso corto y acotado, como los turistas.

Dentro de la perspectiva cuyas distinciones y definiciones se circunscriben al ámbito jurídico-político, comencemos con lo relativo a los conceptos de ciudadanía y de ciudadano. Dado que la precisión del concepto ciudadanía siempre depende de la que se tenga del concepto de ciudadano, es necesario aclarar éste para hacer lo propio con aquél. En efecto, para precisar las dos acepciones más usuales de ciudadanía — conjunto de ciudadanos y estatus o condición propia de los ciudadanos, que a su vez involucra el conocimiento de los atributos que le confieren dicho estatus al ciudadano- es necesario y suficiente establecer con claridad qué se entiende por ciudadano; es decir, cuáles son las características del ciudadano y cómo se le distingue de los otros estratos sociopolíticos contemplados.

Con frecuencia, todos los habitantes de un país tienen en común el disfrute de ciertos derechos individuales y sociales, pero los derechos políticos siempre son exclusivos de una parte de ellos; es decir, siempre hay una porción amplia de habitantes sin derechos políticos, como los menores de edad y, en su caso, los inmigrantes. ${ }^{11}$ A partir de los criterios jurídicopolíticos que ahora interesan, los habitantes se clasifican de la siguiente manera: en principio, se distingue entre nacionales e inmigrantes, pero los nacionales, a su vez, se dividen en dos conjuntos: los ciudadanos en sentido restringido (para distinguirlos de los que desde la perspectiva ético-política llamaré ciudadanos en sentido amplio) y los súbditos (en el sentido de nacionales sin derechos políticos), que se subdividen en menores de edad y ciudadanos con los derechos políticos suspendidos.

Por tanto, los nacionales son los que tienen la nacionalidad del país donde viven y los inmigrantes son los que no la tienen (que actualmente equivale a decir que la tienen de un país distinto a aquél donde radican). Generalmente, esta diferencia se traduce en que los nacionales pueden disfrutar de más derechos individuales y sociales que los inmigrantes, al tiempo que la obtención de la ciudadanía es distinta en ambos casos. La casi totalidad de los nacionales de origen (por nacer en el territorio o por ascendencia) sin ciudadanía se compone de menores de edad que, para adquirir la ciudadanía, sólo requieren tener la edad que marca la legislación de su país y hacer algún sencillo trámite administrativo. Por su parte, el inmigrante, para tener los derechos políticos propios de la ciudadanía, debe previamente adquirir, por naturalización, la nacionalidad del país donde reside, lo que con frecuencia no resulta fácil. Además, la relación con el país donde radican es distinta en uno y otro caso, pues, entre otras cuestiones, en general el nacional tiene un sentimiento de pertenencia más intenso hacia él que el inmigrante, por lo que el primero suele inclinarse más a la 
participación que el segundo, quien, además, como se indicó, tiene limitaciones jurídicas al respecto.

Los aquí llamados súbditos, a falta de otra denominación mejor, son los nacionales que no gozan de derechos políticos; es decir, los menores de edad —los más importantes, sin duda, cuantitativamente- y los ciudadanos a quienes se han suspendido los derechos políticos. Esta suspensión puede tener razones como las siguientes: de orden judicial, enajenación mental, alistamiento en las fuerzas armadas e ingreso al clero (Borja, 2002: 178). Cuando tales causas dejan de existir, el súbdito recupera su calidad de ciudadano. Por su parte, los ciudadanos en sentido restringido - comúnmente llamados ciudadanos, sin más, desde la óptica jurídicopolítica- son los únicos que pueden ejercer los derechos políticos en el país del que se trate. Los ciudadanos en sentido restringido son necesariamente nacionales, pero su nacionalidad, como se indicó, pudo ser adquirida por nacimiento o por naturalización. Los derechos políticos más elementales son el de participar en la elección de autoridades y el de acceder a cargos de elección popular, pero también lo es el de participar tanto en otros tipos de consultas populares, como el referéndum, como en discusiones y organizaciones políticas (Borja, 2002: 178; Hernández-Rubio, 1987: 398-399).

Aunque no lo hace ninguna de las obras lexicográficas especializadas consultadas, estas distinciones y definiciones en torno a los conceptos de ciudadano (y ciudadanía) permiten hacer distinciones importantes entre los estratos sociopolíticos de los países con regímenes políticos democráticos y los estratos sociopolíticos de los países con regímenes políticos dictatoriales. De esta comparación se deriva a su vez la conveniencia de cierto tipo de reivindicaciones y obligaciones, que mostrarían posibles concreciones del concepto civismo en relación con la perspectiva jurídicopolítica que ahora interesa.

Si entendemos por ciudadano (en sentido restringido), como lo hacen todas las obras lexicográficas especializadas consultadas, el individuo al que se le reconocen, tanto en la legislación como en la práctica, los tres tipos derechos mencionados, debemos concluir que los únicos países con ciudadanos son los gobernados por un Estado social y democrático de derecho, también llamado Estado benefactor y Estado de bienestar. Pongamos algunos ejemplos de tipos de países en los que, por su régimen político, no habría ciudadanos en el sentido indicado. Incluso en algunos de ellos la mayoría de los habitantes, debido al grado de dominación que padece, ni siquiera podría calificarse de súbdita, sino que habría que acudir a denominaciones, como la de siervo, que denota no sólo la total exclusión de derechos políticos, sino también cierta negación de derechos individuales básicos y por tanto de, para catalogar al estrato sociopolítico al que pertenecen. ${ }^{12}$ Bajo las dictaduras los derechos individuales y políticos, independientemente de que estén o no contemplados en la legislación, no son reconocidos en la realidad, si bien cabe sostener que en general en las dictaduras de derecha tampoco son reconocidos los derechos sociales, mientras 
en las dictaduras de izquierda, como las leninistas, éstos son reconocidos más frecuentemente. También cabe mencionar que, en la primera mitad del siglo XIX, en las democracias liberales ni siquiera la legislación reconocía derechos sociales (ni tampoco políticos) a la mayoría de la población adulta.

De acuerdo con este planteamiento, la perspectiva jurídico-política de ciudadanía puede amparar reivindicaciones de suma importancia. Incluso en los países donde el Estado social y democrático de derecho ha sido más abarcador siempre habrá déficits relacionados con alguno de los tres tipos de derechos mencionados, máxime si se considera que la concepción de tales derechos en ocasiones se amplia con el correr del tiempo. Si además de los derechos contemplamos las obligaciones que suelen ir aparejadas a ellos, el panorama de metas por obtener dentro de esta misma perspectiva se amplia considerablemente, incluso, reitero, en estos mismos países, pues siempre hay porciones importantes de individuos que tienden al incumplimiento de las mismas. Las reivindicaciones que se derivan de esta perspectiva en relación con las dictaduras, lo mismo las de izquierda que las de derecha, son, lógicamente, de mucha más envergadura, pues en estos regímenes políticos la primera exigencia que se plantea es el reconocimiento de los derechos individuales y políticos que sistemáticamente se les niega a los habitantes. Y esta reivindicación no puede por menos que conducir, necesariamente, a la exigencia del desmantelamiento del régimen político imperante y su sustitución por otro de carácter democrático, porque ésta es la única posibilidad de que los habitantes adultos pasen de su condición de siervos o súbditos a la de ciudadanos. De esta manera, en las dictaduras, desde la perspectiva jurídico-política, el civismo se puede asociar, en tanto que justifique la pretensión de instaurar un régimen político que reconozca derechos individuales y políticos, con la lucha por transitar hacia la democracia.

Sin embargo, aunque del enfoque jurídico-político se pueda inferir la conveniencia de expandir y fortalecer los derechos individuales, políticos y sociales, no proporciona el marco conceptual adecuado (especialmente, por la ausencia de los conceptos que enseguida se denominarán ciudadano en sentido amplio, ciudadano democrático y ciudadano ideal) para plantear con la debida claridad y profundidad tales objetivos, que, en definitiva, también son el desiderátum de toda concepción actual de ciudadanía que incluya como uno de sus elementos centrales el civismo que deben mostrar los ciudadanos.

Veamos, pues, las distinciones y definiciones correspondientes a la concepción ético-política de ciudadanía, así como las consecuencias que de ellas se derivan para guiar la conducta de los ciudadanos. El esquema que se propone respecto a esta concepción tiene como eje el ciudadano democrático: además de caracterizarlo, a través de actitudes y comportamientos guiados por determinados valores, dicho esquema pretende diferenciarle de otros tipos de ciudadanos, establecer el universo de los buenos ciudadanos potenciales (que marca sus posibilidades máximas de expansión y que denomino ciudadanía en sentido amplio) y su función, de pro- 
tección y fortalecimiento, tanto ante los ciudadanos más vulnerables como respecto a los que no tienen la madurez adecuada para participar en la vida pública, que denomino niños. Como puede observarse, lo propuesto desde este enfoque, todavía en mayor medida que lo referido al enfoque jurídicopolítico, no sólo tiene un interés cognitivo, sino que además pretende servir de base para proyectar y llevar a cabo acciones concretas encaminadas a la construcción de ciudadanía; es decir, a la expansión y fortalecimiento de buenos ciudadanos, tarea que debe involucrar a quienes todavía no lo son pero lo serán con el paso del tiempo: los niños.

La primera división del universo de habitantes basada en esta concepción ético-política —basada en el criterio de la madurez psicológica, que de alguna manera se corresponde con uno etario- distingue los niños o habitantes todavía inmaduros para participar activamente en la vida política de los ciudadanos en sentido amplio, independientemente de que unos y otros sean nacionales o extranjeros. Las tres distinciones siguientes se refieren a los ciudadanos en sentido amplio — estrato sociopolítico que, por supuesto, incluye al de los ciudadanos en sentido restringido, por lo que también éstos pueden clasificarse de la misma forma-y se establecen a partir de la participación de los ciudadanos en los asuntos públicos o, más concretamente, en la toma de decisiones colectivas, lo que ineludiblemente remite no sólo al ámbito de las actitudes y las ideas, sino también al de la actuación, de la conducta o del comportamiento.

La segunda distinción divide al conjunto de ciudadanos en sentido amplio en ciudadanos activos y pasivos, de acuerdo, básicamente, con el nivel cuantitativo de la mencionada participación. La tercera distinción divide a los ciudadanos activos en gremiales e ideológicos, según sea la amplitud del interés que guíe su participación. Por último, los ciudadanos con intereses ideológicos se dividen en democráticos y autoritarios, de acuerdo con el compromiso que tengan con un régimen político determinado y con los valores o contravalores que tal régimen promueva.

El concepto de ciudadano en sentido amplio tiene la pretensión, como se señaló, de establecer el universo potencial de los ciudadanos democráticos. En general, la mayoría de los ciudadanos en sentido amplio está constituida por ciudadanos en sentido restringido, quienes, además, como también se indicó, suelen ser más propensos a la participación en la política nacional por tener un sentimiento de pertenencia más intenso respecto al país donde viven. Sin embargo, la ciudadanía en sentido amplio no sólo integra a éstos, sino también a todos los otros habitantes de un país con la madurez psicológica suficiente para participar autónomamente en la vida pública, independientemente de que sean nacionales -incluidos los que tienen su ciudadanía jurídica suspendida por motivos no psicológicos- o inmigrantes. Los ciudadanos en sentido amplio son, por tanto, los habitantes de un país que tienen la madurez psicológica suficiente para participar en la toma de decisiones colectivas del país donde viven, lo que implica cierta capacidad de autonomía individual cognitiva y moral. De esta ciudadanía en sentido amplio sólo quedan excluidos los niños (o personas sin la 
madurez psicológica adecuada para participar autónomamente en la vida política del país) y los adultos, irrelevantes cuantitativamente, que tampoco tengan tal madurez.

El ciudadano pasivo se distingue del activo por su nivel de participación. Ésta se puede medir, en principio, a partir de dos tipos de involucramiento político, que se pueden presentar en los ámbitos más diversos (desde el nacional y el municipal hasta el organizacional): en los procesos de selección de autoridades o de quienes toman las decisiones colectivas (por lo menos a través del voto), que sería típico de la participación más común en la democracia participativa, y directamente en los procesos donde se toman tales decisiones, que sería característico de la democracia directa. Si bien a los inmigrantes se les prohíbe llevar a cabo cierto tipo de participación política de la mayor relevancia (la propia de los ciudadanos en sentido restringido), siempre tienen alguna posibilidad jurídica de participación pública, aunque sólo sea la derivada de su interacción con otros inmigrantes. En México el nivel de abstencionismo en las elecciones constitucionales (federales, estatales y municipales) está dentro de lo normal, pero la proporción de ciudadanos que participan, de la manera que sea, en algún tipo de organización es sumamente bajo. Entre 1973 y 2009, la participación en las elecciones federales, tanto presidenciales como legislativas, osciló entre 40\% y 77\% (Valdés, 2010: 28), mientras que "menos de $7 \%$ se interesa o está dispuesto a integrarse a alguna forma de acción colectiva institucionalizada”, desde las asociaciones religiosas, deportivas y de colonos hasta las sindicales y los partidos políticos (Russo, 2010: 2019).

De acuerdo con este planteamiento, se proponen las siguientes definiciones: ciudadano, en sentido amplio, pasivo es aquél que teniendo la madurez psicológica adecuada no participa en los asuntos públicos; ciudadano, en sentido restringido, pasivo es quien no participa en tales asuntos pese a tener no sólo la madurez psicológica para ello, sino también los derechos políticos que le facultan para ello; por último, ciudadano activo (nacional o inmigrante) es aquél que participa en dichos asuntos independientemente de su estatus jurídico-político.

Pero el problema no sólo es cuantitativo, en la participación política se debe enfatizar la calidad o el tipo de dicha participación. Al respecto, es de la mayor importancia si el motivo de la participación consiste sólo en mejorar la situación propia o implica, además o en sustitución de lo anterior, la defensa de propuestas con objetivos más amplios o ideológicos (en el sentido de que defienden sistemas de ideas universales, relacionados con el conjunto del país o de amplios segmentos de sus habitantes). Sin embargo, debe reconocerse que la frontera entre estos dos tipos de participación no es nítida, pues en ocasiones una reivindicación con un interés exclusivamente gremial puede implicar un beneficio colectivo, como puede ser la expansión de cualquiera de los tres tipos de derechos. En este orden de ideas, el ciudadano activo gremial sólo participa en los asuntos públicos para mejorar su situación individual, mientras que el ciudadano activo ideológico actúa en defensa de ideas más abarcadoras. 
Por último, propongo que la división más relevante respecto a los ciudadanos ideológicos es la que diferencia ciudadanos democráticos de ciudadanos autoritarios. Los primeros son los que defienden y fortalecen los valores (como la tolerancia, el respeto, el diálogo y la negociación), las instituciones (el congreso plural, el poder judicial independiente y aquellas otras que contribuyen a limitar institucionalmente el poder del Ejecutivo) y los procesos (elecciones limpias y competidas, así como los distintos procedimientos a través de los cuales los ciudadanos toman decisiones directamente) democráticos. ${ }^{13}$ Por el contrario, los ciudadanos autoritarios son los que denigran y debilitan los valores, las instituciones y los procesos democráticos. Vista desde otro ángulo, esta misma contraposición es la que se plantea al afirmar que el ciudadano democrático es el único que puede defender y promover simultáneamente los derechos individuales, políticos y sociales.

Por supuesto, los ciudadanos democráticos y los ciudadanos autoritarios asumen actitudes distintas según sea el tipo de régimen político en el que viven. La defensa y promoción de los valores democráticos exigen que un ciudadano democrático defienda las instituciones y los procesos democráticos existentes en un régimen democrático y denuncie sus ausencias en un régimen autoritario. Por tanto, en relación con el régimen político, el ciudadano democrático será reformista en una democracia y revolucionario (lo que no implica, por supuesto, el ejercicio de la violencia) en una dictadura, si bien debe enfatizarse que ser reformista no es igual que ser acrítico, pues la defensa y el fortalecimiento de la democracia exigen su perfeccionamiento permanente y éste sólo es posible a partir de la crítica constructiva, es decir, por lo menos, de la denuncia de los procederes insuficientemente democráticos de las instituciones y los procesos democráticos. Por su parte, el ciudadano autoritario denigra y debilita las instituciones y los procesos democráticos existentes en las democracias (demostrando con ello lo dañino de su crítica), pero no necesariamente defiende cualquier tipo de autoritarismo, pues ha sido frecuente que luche por derribar una dictadura concreta (por ejemplo, de derecha) para imponer otra (por ejemplo, de izquierda).

Nótese que al describir al ciudadano democrático (incluso en el terreno sociológico, no ideal, al que por ahora procuro sujetarme) no sólo me he remitido a instituciones y procesos, sino también a valores. Esto es así porque la defensa de las instituciones y los procesos democráticos sólo cobra su verdadero sentido a partir de la conciencia de que, a través de dicha defensa, en realidad se están promoviendo valores estrictamente democráticos, como la libertad, la igualdad jurídica, la pluralidad, la tolerancia, el respeto, el diálogo, la negociación, la pluralidad y la participación (en el sentido estricto de este término, como involucramiento en la toma de decisiones colectivas, lo que lo diferencia de la movilización), pues las instituciones y los procesos democráticos sólo tienen sentido en tanto que encarnan tales valores. Sin duda, esta encarnación siempre será parcial, pues los valores, por definición, nunca se llevan a la práctica plenamente, lo que, por otra parte, explica tanto el carácter siempre perfectible de las 
realidades humanas que, como la democracia, en ellos se fundan como la necesidad de criticarlas para mejorarlas. Por su parte, la maldad de las dictaduras radica en que sus instituciones y procesos se basan en los contravalores que se oponen a los valores democráticos mencionados antes, como la intolerancia, la represión, la violencia y la discriminación.

Ahora bien, si esto es así, si el comportamiento del ciudadano democrático sólo tiene sentido en tanto que está guiado por valores democráticos, es dable establecer dos deducciones. Por un lado, el ciudadano democrático tiende a alcanzar niveles de desarrollo moral relativamente elevados, puesto que éstos se caracterizan por no actuar con base en las recompensas o los castigos esperados ni para satisfacer expectativas de determinados grupos sociales (como la familia o la nación), sino, precisamente, de acuerdo con valores morales asumidos personalmente, con independencia de los grupos que los profesan, y considerados benéficos para todas las personas que componen la sociedad (Kohlberg, 1981). ${ }^{14}$

Por otro lado, dado que los valores que guían al ciudadano democrático son los mismos que fincan una interacción respetuosa y pacífica en la vida cotidiana (Lizcano, 2010a), es dable afirmar el ciudadano democrático, aquél cuya conducta se guía por valores democráticos, además de tender al comportamiento político señalado, tiende a la interacción respetuosa y pacífica en los distintos ámbitos en que se desenvuelve su vida cotidiana, como el familiar, el escolar y el laboral. De esta forma, se podría afirmar, inicialmente, que el ciudadano democrático es aquél cuya vida, tanto en lo público como en lo privado, se orienta a partir de valores democráticos.

Pero todavía se puede hacer una deducción más para llegar a sostener algo más abarcador: la conducta del ciudadano democrático tiende a guiarse por un conjunto de valores más amplio que los estrictamente democráticos, pues estos están íntimamente vinculados con valores relativos a otros aspectos de la realidad. Veamos -de la forma más sucinta posiblealgunas de estas relaciones, que parten del convencimiento de que es posible y deseable la defensa simultánea de los distintos tipos de valores y, por tanto, de la crítica de aquellos planteamientos que, coactivamente, oponen unos valores a otros, como, paradigmáticamente, la libertad y la igualdad. La interacción democrática (la que gira en torno a un ejercicio del poder respetuoso y dialogante) debe imperar tanto en la esfera del régimen político o pública (donde la participación debe regirse por la libertad, la igualdad jurídica, la legalidad, la pluralidad, la tolerancia, el respeto, el diálogo y la negociación) como en la esfera de la vida cotidiana o privada (guiada por la libertad, el respeto, el diálogo y la negociación). La participación democrática en el ámbito público exige demandar, criticar (además de construir), pero tales acciones no podrán llevarse a cabo adecuadamente sin un nivel elevado de desarrollo cognitivo y moral (que involucra valores asociados con el sujeto autónomo cognitiva y moralmente, cuando no también con la felicidad) y sin la autoridad moral que proviene del cumplimiento satisfactorio de las obligaciones contraídas en la esfera privada (al que alu- 
de el valor de la responsabilidad). ${ }^{15}$ Por su parte, la solidaridad con los más débiles no es sólo un asunto de justicia: la defensa de los derechos individuales (combatiendo en especial la violencia) y sociales de los grupos vulnerables en general y de los niños en particular constituye un factor indispensable para la perpetuación y expansión de la ciudadanía a través del tiempo. Pero la perspectiva de futuro debe ser más amplia que la referida a la generación más inmediata y abarcar el aspecto que puede deteriorar en mayor medida la vida humana, por lo que debemos defender un medio ambiente sosteniblemente saludable para las generaciones futuras.

De acuerdo con lo anterior, se cierra este trabajo con dos definiciones que, si bien se derivan de lo dicho en el plano sociológico propio del concepto estrato sociopolítico, se enmarca en el terreno de la ética, de lo ideal, del deber ser, al expresar global y plenamente lo que en la realidad aparece fragmentaria y parcialmente. Pese a que los diccionarios de la lengua y las obras lexicográficas especializadas, como vimos, definen civismo como actitudes y comportamientos específicos, no parecería disparatado recuperar el significado usual en el ámbito pedagógico, que se refiere a un conjunto de valores, actitudes y comportamientos. Sin embargo, no hay consenso respecto a los ámbitos de la realidad ni al tipo de valores, actitudes y comportamientos involucrados en este concepto. Al respecto propongo que, para cumplir adecuadamente con su inevitable y laudable ingrediente normativo, se entienda civismo como el área del saber, de naturaleza interdisciplinaria, que promueve valores - junto con las actitudes y comportamientos que de ellos se derivan tanto en el ámbito público como en el privado-relativos a la interacción democrática (libertad, igualdad jurídica, pluralidad, tolerancia, respeto, diálogo, negociación, pluralidad y participación), al cabal cumplimiento de las obligaciones aparejadas a los distintos papeles sociales que desempeñamos (responsabilidad familiar, escolar, laboral, etcétera), a la autorrealización (sujeto autónomo cognitiva y moralmente, así como felicidad), a la ayuda al más débil (solidaridad) y ala defensa de un medio ambiente saludable y sostenible.

En este mismo orden de ideas, el ciudadano ideal (al que las personas más ejemplares se aproximan sin poder encarnarlo plenamente)es aquél cuyas actitudes y comportamientos, tanto en el ámbito público como en el privado, se ajustan a los valores relativos a la interacción democrática (libertad, igualdad jurídica, pluralidad, tolerancia, respeto, diálogo, negociación, pluralidad y participación), al cabal cumplimiento de las obligaciones aparejadas a los distintos papeles sociales que desempeñamos (responsabilidad familiar, escolar, laboral, etcétera), a la autorrealización (sujeto autónomo cognitiva y moralmente, así como felicidad), a la ayuda al más débil (solidaridad) y a la defensa de un medio ambiente saludable y sostenible. De esta forma, el ciudadano ideal, caracterizado por cumplir plenamente con obligaciones que van mucho más allá de lo prescrito por la ley, ostentaría el máximo nivel de desarrollo moral según el planteamiento de Kohlberg. 


\section{Conclusiones}

Las conclusiones principales del presente artículo se refieren a tres cuestiones: la comparación de las clasificaciones empleadas para ordenar e interpretar los contenidos de los dos tipos de obras que le sirvieron de principal fuente de información - los diccionarios de la lengua y las obras lexicográficas especializadas-, la comparación de lo dicho sobre las distintas obras lexicográficas especializadas, y la importancia del enfoque ético-político.

En cuanto a la primera cuestión, por poner de relieve los dos universos temáticos principales involucrados en los tres conceptos analizados en el presente artículo — ciudadano, ciudadanía y civismo-, subrayo la correspondencia existente entre los dos campos semánticos diferenciados respecto a las acepciones de los diccionarios de la lengua - la pertenencia a una colectividad, así como la actitud y el comportamiento que deben tener sus integrantes - y los dos enfoques distinguidos respecto a las obras lexicográficas especializadas, el jurídico-político y el ético-político. En efecto, el primer enfoque se refiere a una forma de pertenencia a una colectividad, en tanto que el segundo enfoque incorpora el deber ser derivado de tal pertenencia.

Respecto a la comparación entre las obras lexicográficas especializadas consultadas, que incluyen textos de referencia obligada para los hispanohablantes interesados en distintas disciplinas de las ciencias sociales y las humanidades, sobresalen cinco hechos (más allá de otros de menor trascendencia que pudieran rescatarse, como los relativos al tamaño de las entradas y su diversidad temática): la escasa importancia otorgada a los conceptos analizados en este artículo (casi la mitad, 9 de 19, no incluye ninguno de los tres conceptos como entrada independiente), la exigua relevancia conferida al enfoque ético-político (sólo lo contemplan cuatro de las 11 entradas analizadas), la frecuencia de la ambigüedad al caracterizar los conceptos en cuestión (justificable en los diccionarios de la lengua por tener que reflejar el uso que los hablantes dan a las palabras, pero criticable en los textos científicos), los méritos de varios de ellos (precisión conceptual, capacidad de síntesis y riqueza informativa) y la necesidad de conjugar lo dicho en varias entradas para obtener la información y la claridad adecuadas.

Por último, el enfoque ético-político, pese a ser poco tratado, como acabamos de ver, en las obras lexicográficas especializadas, resulta indispensable para enfrentar adecuadamente la construcción de ciudadanía; es decir, uno de los desafíos más urgentes en el mundo actual. Del éxito en esta empresa depende en gran medida tanto la expansión y consolidación de la democracia como la ampliación y profundización de la interacción humana respetuosa y dialogante; cuestiones ambas de las que a su vez depende, en una parte por lo menos igual a la que lo hace del desarrollo socioeconómico, el bienestar y la felicidad de las personas. Por tanto, la ciudadanía no es sólo un atributo que confiere un estatus determinado, como 
revela el enfoque jurídico-político, sino que también es un concepto indispensable, junto con los de ciudadano y civismo, en la tarea de comprender y asumir uno de los retos actuales más importantes no sólo para muchas instituciones y organizaciones fundamentales en las sociedades (como las educativas, las comunicacionales y las políticas), sino también para todas las personas de carne y hueso comprometidas con la mejora de la humanidad. 


\section{Notas}

${ }^{1}$ Entiendo por colectividad todo grupo social (en el sentido de agrupamiento humano susceptible, entre otras cuestiones, de generar sentimientos de pertenencia), con excepción de los denominados grupos primarios como la familia y los que giran en torno a la amistad. Sólo en el seno de una colectividad puede conformarse una comunidad política; es decir, un conjunto relativamente amplio de individuos que toma decisiones vinculantes relativas a su colectividad o que selecciona a quienes las toman, lo que implica el disfrute de los derechos de expresión, reunión y asociación. Las colectividades se clasifican en soberanas (cuyas manifestaciones a lo largo de la historia de la humanidad pueden dividirse en sociedades simples, sociedades agrícolas complejas, imperios agrícolas, Estados nacionales e imperios industriales) y políticamente dependientes, que forman parte de las colectividades soberanas, como las comunidades locales (como los pueblos, las ciudades y los municipios), integradas por familias, y las organizaciones, compuestas básicamente por adultos (Lizcano, 2004: 10-12; Lizcano, 2007: 63-68).

${ }^{2}$ De todas las acepciones de las tres palabras consultadas en los tres diccionarios, sólo he prescindido de una, por no relacionarse con el objeto de estudio del presente texto: la que, en asuntos legales, entiende ciudadano como "hombre bueno" o "el mediador en los actos de conciliación” (RAE, 2012b).Las demás se reproducen íntegramente, lo que permite comprobar, entre otras cuestiones, que en general las definiciones de la RAE son menos detalladas que las de los otros dos diccionarios seleccionados, los cuales, además, proporcionan ejemplos de uso, que no proporciona la RAE.

${ }^{3}$ En la vigésima segunda edición de este diccionario, estas dos acepciones aparecían unidas - "habitante de las ciudades antiguas o de los Estados modernos como sujeto de derechos políticos y que interviene, ejercitándolos, en el gobierno del país”- y se añadía otra de sentido restringido y que aludía al pasado: "aquel que en el pueblo de su domicilio tenía un estado medio entre el caballero y el trabajador manual” (RAE, 2012a).

${ }^{4}$ Esta clasificación no coincide, como era de esperar, con la que se podría hacer a partir de la autoidentificación de las obras lexicográficas consideradas, pues 15 se autoidentifican como diccionarios, 3 como enciclopedias y 1 como léxico.

${ }^{5}$ De estas 19 obras lexicográficas, sólo de una (Abbagnano, 2008) hablo tanto en la parte del apartado donde se indica qué dicen de los conceptos en cuestión como en la parte, al final del mismo, donde se reseñan las que no contienen ninguna de las tres entradas, debido a que en las ediciones elaboradas directamente por Abbagnano no se incluía ninguna de ellas, pero en la reedición actualizada y aumentada por Giovanni Fornero se incorporó por primera una entrada vinculada con nuestro objeto de estudio, la de "ciudadanía”.

${ }^{6}$ De estas 10 obras lexicográficas, siete fueron concebidas originalmente en español y las tres restantes en alemán (Nohlen, 2006), inglés (Abercrombie, 1986) e italiano (Abbagnano, 2008).

${ }^{7}$ También llamado Estado de bienestar y Estado benefactor, el Estado social y democrático de derecho es el que ha predominado en el mundo desarrollado después de la Segunda Guerra Mundial. El inicio de su generalización se relacionó con las respuestas keynesianas a la dramática crisis económica iniciada en 1929. Esta forma de Estado ha sido la experiencia humana más exitosa en la conjugación de democracia (en este caso, representativa) y desarrollo socioeconómico. 
${ }^{8}$ En esta obra aparecen dos entradas, “ciudadanía” y “ciudadano”, pero nos ceñimos a la primera porque la segunda no añade nada a la primera.

9“Históricamente, la constitución de la ciudadanía se ha entendido como un proceso evolutivo desde la codificación de los derechos civiles, pasando por los políticos, hasta los sociales (Marshall, 1965) proceso que abarca desde el siglo XVIII hasta el siglo XX” (Bobes, 2000: 52).

${ }^{10} \mathrm{Si}$ bien las reflexiones de este apartado, con las adecuaciones correspondientes, podrían aplicarse tanto a colectividades dependientes políticamente como a conjuntos de países, este ejercicio se deja para otra ocasión.

${ }^{11}$ Como puede observarse, para establecer similitudes y diferencias entre los estratos sociopolíticos utilizo, retomando el planteamiento de Borja (2002: 176-177), la famosa clasificación de derechos de Marshall, quien, como vimos en el apartado anterior, los divide en tres conjuntos: individuales, políticos y sociales.

${ }^{12}$ En un texto anterior (Lizcano, 2010b), con la finalidad de clasificar los regímenes políticos democráticos, distingo cuatro tipos de estrato sociopolítico: esclavo, siervo, súbdito y ciudadano.

${ }^{13}$ En un texto anterior (Lizcano, 2011: 37) sostengo que el criterio más importante en orden a detectar el talante democrático o autoritario de una organización es su actitud ante tres cuestiones fundamentales para establecer el carácter democrático de un régimen político: procesos electorales limpios y competidos; libertades individuales básicas de expresión, reunión y asociación; e instituciones que garantizan tanto los derechos civiles y los derechos políticos como el control de unos poderes estatales sobre otros, en especial sobre el más fuerte de ellos, el poder Ejecutivo.

${ }^{14} \mathrm{~A}$ partir de los planeamientos del mismo Kohlberg, que defiende la relación entre desarrollo moral y desarrollo cognitivo, sería interesante demostrar que el maniqueísmo, en tanto que forma de conocer y valorar todavía ampliamente utilizada, es propia de niveles poco elevados en ambos desarrollos. Pero esto queda pendiente para un trabajo posterior.

${ }^{15}$ Para que no sea calificada de incongruente, la denuncia contra la corrupción y la negligencia de los funcionarios públicos, que constituye una parte relevante de la participación democrática, debe provenir de ciudadanos que cumplan responsablemente con las funciones que desempeñan en el ámbito privado (por ejemplo, en la familia, la escuela y el trabajo); esto es, debe provenir de ciudadanos que no sean corruptos o negligentes. 


\section{Bibliografía}

Abbagnano, Nicola (2008), Diccionario de filosofía, Fondo de Cultura Económica, $2^{a}$ reimp.de la $3^{\mathrm{a}}$ reed., 1103 pp., México,

Abercrombie, Nicholas, Sthephen Hill y Bryan S. Turner (1986), Diccionario de sociología, Cátedra, Madrid,285 pp.

Baca Olamendi, Laura (2000), “Ciudadanía multicultural”, en Laura Baca Olamendi, Judit Bokser-Liwerant, Fernando Catañeda y otros (comps.),Léxico de la política, Fondo de Cultura Económica / FLACSO / SEP / CONACYT / Heinrich BöllStiftung, México, pp. 54-57.

Baca Olamendi, Laura, Judit Bokser-Liwerant, Fernando Catañeda y otros (comps.) (2000),Léxico de la política, Fondo de Cultura Económica / Flacso / SEP / Conacyt / Fundación Heinrich Böll, México, 831 pp.

Barfield, Thomas (ed.) (2000), Diccionario de antropología, Siglo XXI, México, 652 pp.

Blasco Quintana, Juan (1987), “Ciudadano”, en Salustiano del Campo (dir.), Diccionario UNESCO de ciencias sociales, Planeta-Agostini, Barcelona,vol. I, pp. 399-400.

Bobbio, Norberto, Nicola Matteucci y Gianfranco Pasquino (dirs.) (2002), Diccionario de política, Siglo XXI, México, $13^{\mathrm{a}}$ ed., 2 vols.

Bobes, Velia Cecilia (2000), “Ciudadanía”, en Laura Baca Olamendi, Judit Bokser-Liwerant, Fernando Catañeda y otros (comps.),Léxico de la política, Fondo de Cultura Económica / FLACSO / SEP / CONACYT / Heinrich BöllStiftung, México, pp. 50-53.

Bonte, Pierre y Michel Izard (2005), Diccionario Akal de etnología y antropología, Akal, Madrid, 758 pp.

Borja, Rodrigo (2002-2003), Enciclopedia de la política, Fondo de Cultura Económica, México, $3^{\mathrm{a}}$ ed. corr. yaum., 2 vols.

Campo, Salustiano del (dir.), Diccionario UNESCO de ciencias sociales, Planeta-Agostini, Barcelona, 4 vols.

Canto-Sperber, Monique (dir.) (2001), Diccionario de ética y de filosofía moral,Fondo de Cultura Económica, México,2 vols.

Fairchild, Henry Pratt (ed.) (2006), Diccionario de sociología, Fondo de Cultura Económica, México, $4^{\mathrm{a}}$ reimp., 320 pp.

Ferrater Mora, José (1990), Diccionario de filosofía, Alianza, Madrid,7ª reimp., 4 vols. 
Galeazzi, Giancarlo (2008), “Ciudadanía”, en Nicola Abbagnano, Diccionario de filosofía, Fondo de Cultura Económica, México, 2ª reimp., p. 168.

Gallino, Luciano (2001), Diccionario de sociología, Siglo XXI, México, $2^{\mathrm{a}}$ ed., 1003 pp.

García Cabeza, Soledad (1998), “Ciudadanía”, en Salvador Giner, Emilio Lamo de Espinosa y Cristóbal Torres (eds.), Diccionario de sociología, Alianza, Madrid, pp. 107-108.

Giner, Salvador, Emilio Lamo de Espinosa y Cristóbal Torres (eds.), Diccionario de sociología, Alianza, Madrid, 1998, 895 pp.

González Vega, Javier (2009), “Ciudadanía europea”, en Román Reyes (dir.) Diccionario crítico de ciencias sociales. Terminología científico-social, Plaza y Valdés / Universidad Complutense de Madrid, Madrid, pp. 323-333.

Hernández-Rubio Cisneros, José María (1987), “Ciudadanía”, en Salustiano del Campo (dir.), Diccionario UNESCO de ciencias sociales, PlanetaAgostini, Barcelona, vol. I, pp. 396-399.

Kohlberg, Lawrence (1981), The Philosophy of Moral Development: Moral Stages and the Idea of Justice,Harper \& Row, San Francisco,441 pp.

Lara Ramos, Luis Fernando (dir.) (2010), Diccionario del español de México, El Colegio de México, México,2 vols.

Lizcano Fernández, Francisco (2011), “Autoritarismo y democracia en las organizaciones (instituciones estatales, partidos políticos y asociaciones de intereses)”, en Francisco Lizcano Fernández (coord.), Democracia en el Estado de México: fortalezas y debilidades,Miguel Ángel Porrúa / UAEM / Contraloría de Poder Legislativo de la LVII Legislatura del Estado de México, México/Toluca, 2011, pp. 11-40.

Ídem (2010a), “La realización individual como centro del devenir humano”, en Lorenzo Peña, TxetxuAusín y Óscar Diego (eds.), Ética y servicio público, Plaza y Valdés, Madrid,pp. 233-267.

Ídem (2010b), “La democracia y su clasificación”, en Elio Masferrer Kan, Elizabeth Díaz Brenis y otros (eds.), Memorias del $53^{\circ}$ ICA. $53^{\circ}$ Congreso internacional de americanistas. Los pueblos americanos: cambios y continuidades. La construcción de lo propio en un mundo globalizado, Universidad Iberoamericana, México, pp. 1-12. Disco Compacto. ISBN 978607-00-0484-1.

Ídem (2007), “Clasificación de las experiencias democráticas de la historia universal”, en Contribuciones desde Coatepec, año VII, núm. 13, Toluca, UAEM, julio-diciembre, pp. 61-76. 
Ídem (2004), "Las etnias centroamericanas en la segunda mitad del siglo XX”, enRevista Mexicana del Caribe, año IX, núm. 17, Chetumal, Quintana Roo, México, enero-junio, pp. 7-66.

López Martínez, Mario (dir.) (2004), Enciclopedia de paz y conflictos, Universidad de Granada / Junta de Andalucía, Granada,2 vols.

Marshall, Thomas Humphrey (1997), “Ciudadanía y clase social”, en Revista Española de Investigaciones Sociológicas, núm. 79, Centro de Investigaciones Sociológicas, Madrid, julio-septiembre, pp. 297-344.

Martínez de Sousa, José (1995), Diccionario de lexicografía práctica,Biblograf, Barcelona, 380 pp.

Martínez Guzmán, Vicent (2004), “Ciudadanos del mundo”, en Mario López Martínez (dir.), Enciclopedia de paz y conflictos, Universidad de Granada / Junta de Andalucía, Granada, pp. 124-127.

Nohlen, Dieter (dir.) (2006a), Diccionario de ciencia política, Porrúa / El Colegio de Veracruz, México, 2 vols.

Nohlen, Dieter (2006b), “Civilidad/civismo”, en DieterNohlen (dir.), Diccionario de ciencia política, Porrúa / El Colegio de Veracruz, México, pp. 203-204.

RAE (Real Academia Española) (2012a), Diccionario de la lengua española, vigésima segunda edición, http://www.rae.es, consultado el 21 de enero.

Ídem (Real Academia Española) (2012b), Diccionario de la lengua española, avance de la vigésima tercera edición, http://www.rae.es, consultado el 21 de enero.

Reyes, Román (dir.) (2009), Diccionario crítico de ciencias sociales. Terminología científico-social,Plaza y Valdés / Universidad Complutense de Madrid, Madrid, 4 vols.

Rieger, Günter (2006), “Ciudadanía/ciudadanos”, en DieterNohlen (dir.), Diccionario de ciencia política, Porrúa / El Colegio de Veracruz, México, pp. 204-205.

Russo Foresto, Juan José (2010), "Participación política y civilidad: la desvinculación”, en Juan José Russo Foresto (coord.), Calidad democrática, formación ciudadana y comportamiento electoral, Instituto Federal Electoral / Consejo Nacional de Ciencia y Tecnología, México, pp. 211256.

Sánchez García, Antonio (2004), “Ciudadanía”, en Mario López Martínez (dir.), Enciclopedia de paz y conflictos, Universidad de Granada / Junta de 
Andalucía, Granada, pp. 123-124.

Sills, David L. (1979), Enciclopedia internacional de las ciencias sociales, Aguilar, Madrid, $2^{\mathrm{a}}$ reimp., 11 vols.

Schoeck, Helmut (1985), Diccionario de sociología, Herder, Barcelona, $760 \mathrm{pp}$.

Tella, Torcuato S. di (coord.) (1989), Diccionario de ciencias sociales y políticas,Puntosur, Buenos Aires, 659 pp.

Valdés Zurita, Leonardo (2010), “Cambio institucional y participación ciudadana”, en Benjamín Revuelta y Fernando Patrón (coords.), Democracia participativa: visiones, avances y provocaciones, Universidad de Guanajuato / Instituto Federal Electoral / Universidad Michoacana de San Nicolás de Hidalgo, México, pp. 13-33.

Vox (2012), Diccionarios gratuitos, Larousse, http://www.diccionarios.com, consultado el 21 de enero.

Wikipedia (Wikipedia. La enciclopedia libre) (2012), “Diccionario de filosofía de Ferrater Mora”, Fundación Wikimedia, http://es.wikipedia.org, consultado el 28 de enero.

Recibido: 21.03.2012

Aceptado: 25.07.2012 